\title{
An Investigation on the Relationship Between Celebrities' Ideal Body Images on Social Media and Young Generation's Body Dissatisfaction
}

\author{
Jing Chen ${ }^{1, *}$ \\ ${ }^{1}$ Guangzhou Foreign Language School, Guangzhou, Guangdong, China \\ *Email: floracjing@gmail.com
}

\begin{abstract}
The current research was conducted to examine whether celebrities on social media intensify body dissatisfaction of the young generation or not. Young people aged from 18 to 24 years old from the top three cities in South, North, and East China were investigated by a survey experiment. Unlike previous studies, my finding took both behaviors and mental states into consideration when drawing conclusions on the degree of body dissatisfaction. This research demonstrated that both sexes became more unsatisfied with their bodies mentally. In addition, surprising results about the impacts of body dissatisfaction on specific body parts dissatisfaction between sex were discovered. The outcome showed, comparing to other body parts, females disliked their shoulders and chests more, while males disliked their thighs and stomachs more, being the opposite to the stereotypes. Nonetheless, only males would alternate their behaviors, such as exercising, to cope with the dissatisfaction. Thus, counterintuitively, ideal body images did not harm people's healths physically. It is convincing to deduce that reducing exposure of ideal body images is incapable of relieving body anxiety and physical health problems like eating disorders.
\end{abstract}

Keywords: body dissatisfaction, body images, social media, young generation

\section{INTRODUCTION}

Mental and physical healths are always been regarded as the paramount factors for people in the present modern but stressful society. Previous findings demonstrated that celebrities led to higher body dissatisfaction among young people after great exposure to social media. Accordingly, the impact harmed young people's healths both mentally and physically [22].

With the widespread popularization and internalization of social media, enhanced attachment with celebrities caused young people to be impacted through both internalization and appearance comparison $[1][3][4][8][16][29]$. After the exposure to social media, ideal body images of celebrities would be internalized and left in young people's minds. In the meanwhile, people tended to compare their own appearances with these received images and further developed body dissatisfaction.

However, preceding findings naturally assumed the preferences of ideal bodies between females and males without further examination. For example, they directly speculated females cared more about fat and males cared more about muscles. Furthermore, previous studies neglected the possibility that people would not practice actual changes, such as exercising, to achieve the ideal bodies. The reliable finding had shown that behaviors may deviate from mental states [5]. Nonetheless, in our research, these overlooked aspects were covered with controlled experiments that took place in China, a significant representation of Asian population which had been neglected from the discussion, and tested with valid hypotheses.

\section{LITERATURE REVIEW}

With the increased impacts of celebrities, social media should take how celebrities influence young people's body dissatisfaction into consideration for the future development. Two main causes, which were the internalization of ideal body images from celebrities on social media and appearance comparison between young people and celebrities, gave rise to body dissatisfaction among the young generation. 
On one hand, previous studies measured media exposure and internalization of ideal body image to examine the relationship between celebrities and young people's body dissatisfaction [1][8][29]. Social media was always been considered a powerful factor that impacts people's healths mentally and physically [22]. With the great amount of exposure to social media, gender stereotypes of ideal bodies displayed by celebrities are reinforced, which are known as the internalization that formed by continuous exposure of ideal body images. That is, media exposure and internalization of ideal body image were assumed to be positively correlated. Based on Tiggemann \& Slater's research [31], greater social media exposure, as well as higher internalization level, led to greater pressure and body dissatisfaction.

On the other hand, previous findings measured the levels of appearance comparison to prove the negatively correlated relationship between peers and young people's body dissatisfaction [3][4][16][29]. They examined the effects by assuming that celebrities only offered ideal body image sources, while social media provided the opportunities for exaggerated internalization of ideal body images, and peers were seemed as reference groups to invoke peers' appearance comparison. However, according to reference group theory [32], individuals considered multidimensional factors when choosing comparative reference groups. Apart from closed relationships like peer friends, parasocial relationships with celebrities were able to resemble closed relationships and acted as the comparative reference group as well [7][21]. Previous studies had already found that appearance comparison was positively correlated with body dissatisfaction. It is reasonable to hypothesize that young people took celebrities as friends because of the illusion of parasocial intimacy [6][25]. With the increasing popularity of social media, more celebrities tended to make use of social media, such as Youtube and Instagram, to shorten the distances and grow an attachment with fans by posting photos and scheduling living regularly [6][17][[26]. As a result, celebrities contributed to young people' body dissatisfaction also by involving appearance comparison instead of simply being as internalization sources of ideal body images.

In sum, both of them contributed to the growing body dissatisfaction after exposure to the celebrities' ideal body images among the young generation.

For ages, the body standards for females and males were thinness and strengths [20][23]. Even though this ideal body standard still seemed prevalent, it is precautious to reconfirm. Base on previous studies, we predicted:

H1a. Young females consider themselves as overweighted more after exposure to a celebrity's workout image.
H1b. Young males consider themselves as lack muscles more after exposure to a celebrity's workout image.

Furthermore, only a few studies actually tested which specific body parts that females and males referred to during appearance comparisons. Considering different ideal body images females and males faced, the cases should be taken separately. A previous finding [27] had found that females and males tend to refer to different specific body parts during appearance comparison. For example, females focused more on waists, while males focused more on shoulders. The ideal body images required males to have wider shoulders and thicker chests for ideal masculinity and females to have thinner thighs and flatter bellies for ideal femineity [20][24]. Thus, we predicted:

$\mathrm{H} 2 \mathrm{a}$. Young females care more about their thighs and bellies in comparison to other body parts after exposure to a celebrity's workout image.

$\mathrm{H} 2 \mathrm{~b}$. Young males care more about their chests and shoulders in comparison to other body parts after exposure to a celebrity's workout image.

Further, plenty of findings showed internalized unachievable body image and increased body dissatisfaction would lead to severe mental and physical health problems for both males and females, such as eating disorders and depression, due to strict diet and stress [15][20][28]. As a result, we predicted:

H3a. Young females experience more anxiety when consuming high-calorie food after exposure to a celebrity's workout image.

H3b. Young males experience more anxiety when consuming high-calorie food after exposure to a celebrity's workout image.

Last but not least, according to Bruner and Postman's finding in 1949, behaviors differed from mental states on some occasions due to the discrepancy between psychological mechanisms and perceptual responses. In this case, there is the possibility that, even though people experienced body dissatisfaction and anxiety, they did not put practical effort, such as keeping extreme diets, into pursuing "perfect" body images. Nonetheless, most previous research concluded the behavior of eating disorders, only based on the cognition of food anxiety. Any researches base singularly on the cognitive or behavioral side was biased. Furthermore, the study [13] sharply pointed out most females exposed to ideal body images did not develop eating disorders. This unprecedented finding reminded us to reassure the relationship between cognition and behaviors. In our research, we tested both the mental statuses and the actual behaviors to reflect on the effects appearance comparison brought to people. In addition, referring to $\mathrm{McCabe} \&$ Ricciardelli's finding [20], females tended to lose weight 
by keeping diets and males tended to gain muscles by exercising. Accordingly, considering the gender difference, we predicted:

H4a. Young females keep diets in order to reach for pursuing body image after exposure to a celebrity's workout image.

H4b. Young males exercise in order to reach for pursuing body image after exposure to a celebrity's workout image.

\section{METHODS}

\subsection{Participants}

When choosing subjects, some preceding studies focused on preadolescents [3][14][29][[30], while others focused on college students [4][8][12][19]. This study chose young people aged from 18 to 24 years old as subjects since they had more opportunities to access social media without parents' interference. Research had shown that college students, normally aged from 18 to 22 years old, were the most active group in social media [18]. As a result, the exposure of celebrities was the highest among college students rather than preadolescents. Persuasive findings had shown that exposure to idealbody celebrities was positively correlated with body dissatisfaction [10][11][29]. Because of their independent lives that nobody intervened in their diet choices or schedules, young people aged from 18 to 24 years old had a higher probability to experience extreme eating disorders and celebrities worship manner, pursuing extreme body shapes blindly.

313 young people were chosen randomly by the datacollecting company Wenjuanxing. Wenjuanxing's pool was filled with volunteers who were willing to take the questionnaires. I sampled from the pool with selection criteria, such as ages and living cities. To achieve generalizability, the number of subjects was roughly equally distributed among Beijing, Shanghai, or Guangzhou, which are the top cities in North, East, and South China. The selected cities from different orientations ensured generalizability in China. Excluding the ones who didn't pass the manipulation check (for details, see Research Design), 300 young people were analyzed in our findings. All subjects are young people aged from 18 to 24 years old.

\subsection{Research Design}

The flow of the survey experiment was shown in Figure 1. Firstly, demographic variables (i.e. height, weight, gender) were tested. Individuals were separated according to their gender only when came to the ideal body image and body dissatisfaction scale. According to the social norms, males were expected to grow strong, while females were expected to grow thin. Therefore, questions must be adapted to each situation of social expectations. However, the parallel structure of the body dissatisfaction scale's items was adopted and other scales were controlled to be completely the same to avoid biases.

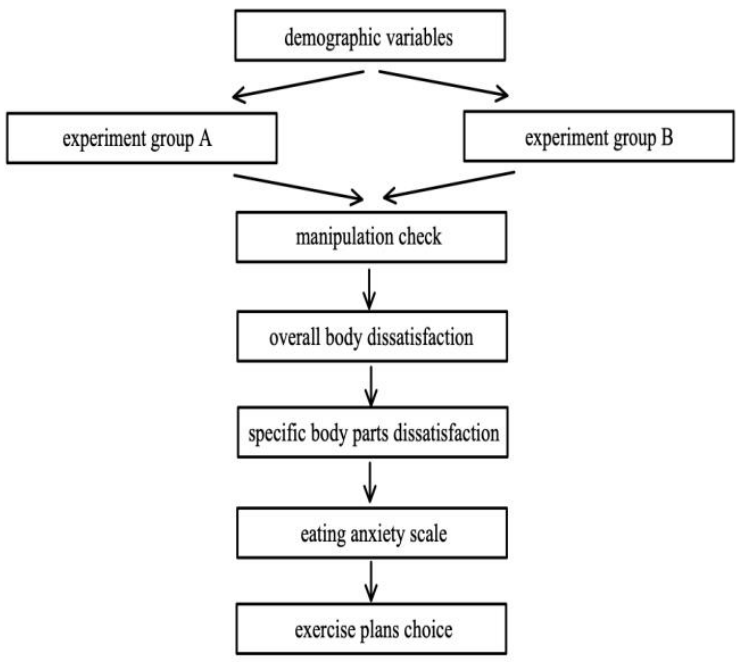

Figure 1 Survey Experiment Flow

After that, subjects were separated into 2 groups, which were experiment group A and experiment group B. In experiment group A, only the head of a celebrity was shown. In experiment group B, a celebrity with an ideal body and her/his meal and exercise plans were shown. The pictures were controlled to be the same celebrity for both groups in order to exclude the bias bring by different celebrities. Manipulation check was tested right after the pictures. The check included multiple choices questions such as "which celebrity you saw just now" and "what kind of photos he/she was sharing" to ensure subjects fully absorb the photo I presented.

\section{Overall body dissatisfaction scale}

This overall body dissatisfaction scale contained 4 items, including 2 items from Eating Disorder Inventory [9] for females and 2 items from the Male Body Attitudes Scale [2] for males. It tested the degree that subjects felt dissatisfied with their own bodies after being exposed to a celebrity's image. Subjects rated on a scale from 1 to 5 ( $1=$ absolutely no, 5=absolutely yes). For females, the items included "I think I have too much fat on my body". For males, the items included "I think I have too little muscle on my body". This study employed a betweensubjects design rather than a within-subjects design. For example, it assumed that all subjects had the same degrees of body dissatisfaction toward themselves before this study. Therefore, the body dissatisfaction scale was only needed to be tested once to draw a conclusion.

\section{Specific body parts dissatisfaction scale}

This specific body parts dissatisfaction scale contained 5 items that covered specific body parts that 
males and females paid greater attention to. It tested the degree that subjects felt dissatisfied with their specific body parts after being exposed to a celebrity's image. Subjects rated on a scale from 1 to 5 (1=absolutely no, $5=$ absolutely yes). For females, the items included "I wish my legs were slimmer". For males, the items included "I wish my arms were stronger".

\section{Eating anxiety scale}

The eating anxiety scale included 1 item, which was "I feel anxious when I consume high-calorie food". The scale aimed to examine the mental health of subjects after being exposed to a celebrity's image in order to prove our hypothesis three. Subjects rated on a scale from 1 to 5 (1=absolutely no, 5=absolutely yes).

\section{Exercise plans choice}

The exercise plan choice included 1 item with 4 choices. Two choices inclined to exercise, while the other two inclined to not exercise. This scale aimed to verify whether subjects would put into practice in order to pursue the ideal body after being exposed to a celebrity's workout image. Subjects chose one among four choices.

\section{RESULTS}

H1a predicted that young females experienced more anxiety when consuming high-calorie food after being exposed to a celebrity's ideal body image. And, H1b predicted that young males experienced more anxiety when consuming high-calorie food after being exposed to a celebrity's ideal body image. Neither H1a nor H1b was confirmed.

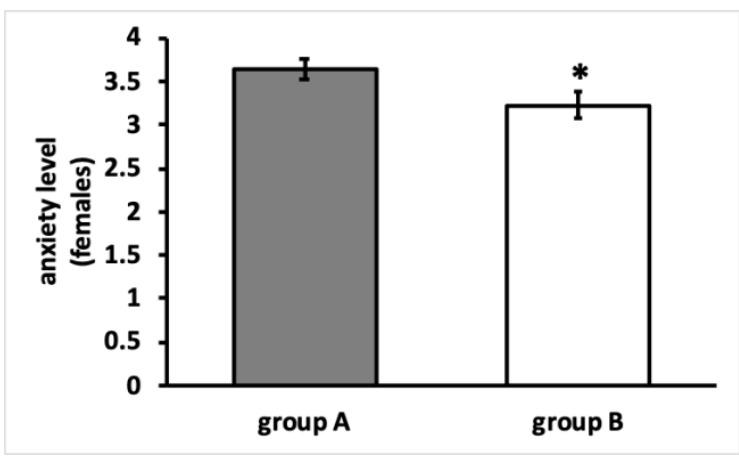

Figure 2 Anxiety when Eating (Females)

As shown in Figure 2, the mean anxiety level of young females for group A was 3.646 and the mean anxiety level of young females for group B was 3.229. Thus, the mean anxiety level was decreased by $11.437 \%$ from group A to group B. The p-value is $1.784^{*} 1 \wedge-26$, which is smaller than the significance level of 0.05 . Therefore, we have $95 \%$ confidence that the mean is significantly decreased from group A to group B.

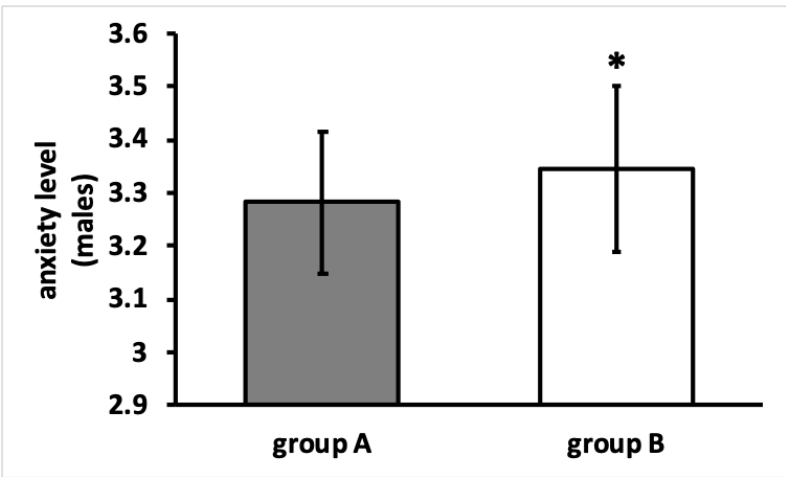

Figure 3 Anxiety when Eating (Males)

While in Figure 3, the mean anxiety level of young males for group A was 3.283 and the mean anxiety level of young males for group B was 3.346. Thus, the mean anxiety level was increased by $1.919 \%$ from group A to group B. The p-value is 0.014 , which is smaller than the significance level of 0.05 . Therefore, we have $95 \%$ confidence that the mean is significantly increased from group A to group B.

Accordingly, it indicated young females' mental anxiety about high-calorie food was negatively correlated with celebrity attachment, while young males' mental anxiety about high-calorie food was positively correlated with celebrity attachment.

$\mathrm{H} 2 \mathrm{a}$ predicted that young females considered themselves as overweighted more. And, H2b predicted that young males considered themselves as lack muscles more. However, neither $\mathrm{H} 2 \mathrm{a}$ nor $\mathrm{H} 2 \mathrm{~b}$ was supported. In the study, young females considered themselves as lack muscles more, while young males considered themselves as over-weighted more.
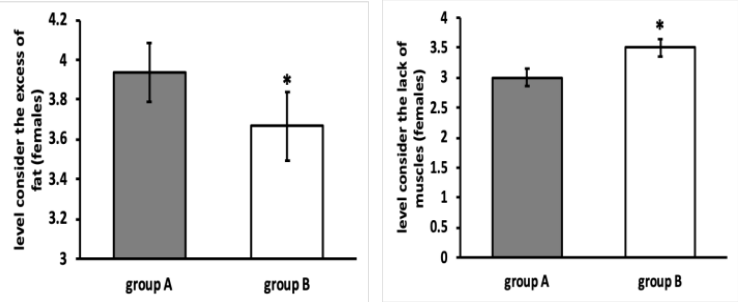

Figure 4 Ways females perceive themselves

As shown in Figure 4, the mean level of young females considered themselves as over-weighted for group $\mathrm{A}$ is 3.938 and the mean level of young females who considered themselves as over-weighted for group B is 3.667 . Thus, the mean level was decreased by $6.882 \%$ from group A to group B. The p-value is $8.759^{*} 10^{\wedge}-13$, which is smaller than the significance level of 0.05 . Therefore, we have $95 \%$ confidence that the mean is significantly decreased from group A to group B. Moreover, the mean level of young females who considered themselves as lack muscles for group A was 3 and the mean level of young females who considered themselves as the lack muscles for group B was 3.5. Thus, 
the mean level was increased by $16.667 \%$ from group A to group B. The p-value is $1.088^{*} 10^{\wedge}-31$, which is smaller than the significance level of 0.05 . Therefore, we have $95 \%$ confidence that the mean is significantly increased from group A to group B.
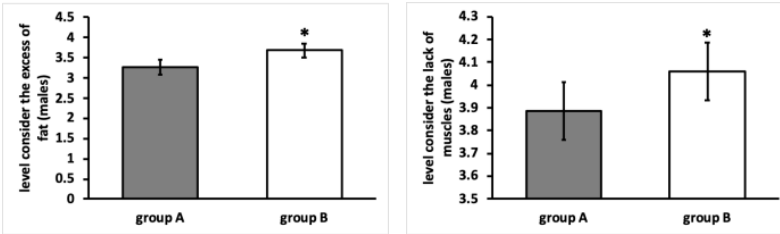

Figure 5 Ways Males perceive themselves

While in Figure 5, the mean level of young males who considered themselves as over-weighted for group A was 3.264 and the mean level of young males considered themselves as over-weighted for group B was 3.673. Therefore, the mean level was increased by $12.531 \%$ from group A to group B. The p-value is $1.5831 * 10^{\wedge}-22$, which is smaller than the significance level of 0.05 . Therefore, we have $95 \%$ confidence that the mean is significantly increased from group A to group B. Besides, the mean level of young males considered themselves as the lack muscles for group A was 3.887 and the mean level of young males considered themselves as the lack muscles for group B was 4.058. Thus, the mean level was increased by $4.399 \%$ from group A to group B. The pvalue is $2.745^{*} 10^{\wedge}-10$, which is smaller than the significance level of 0.05 . Therefore, we have $95 \%$ confidence that the mean is significantly increased from group A to group B.

The result demonstrated young females actually considered themselves as the lack muscles more. On the other hand, young males considered themselves as overweighted more.

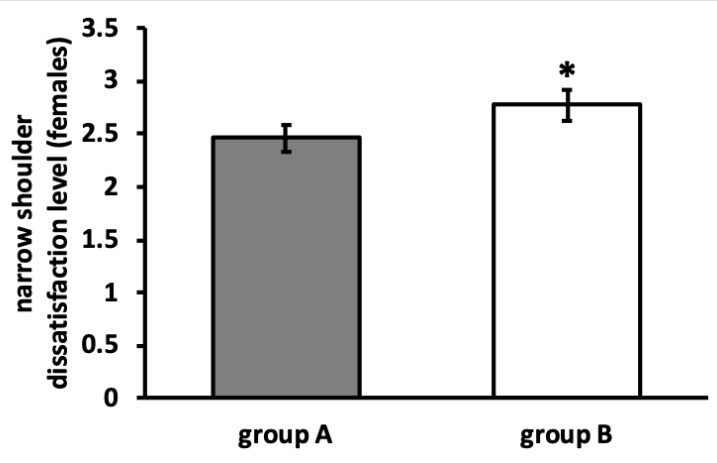

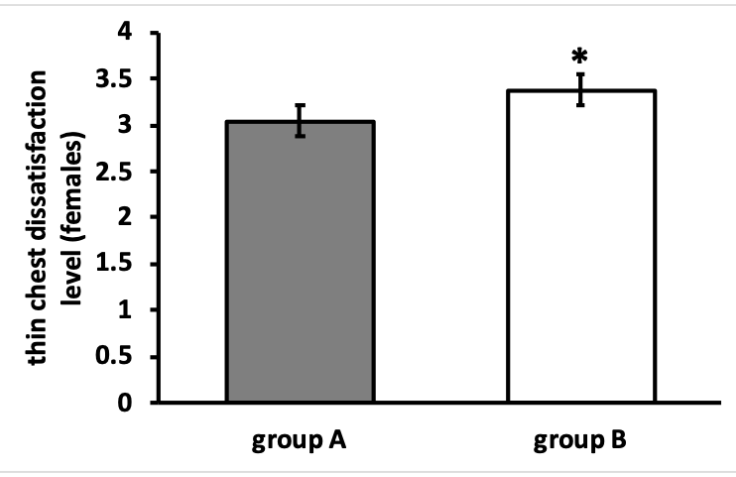
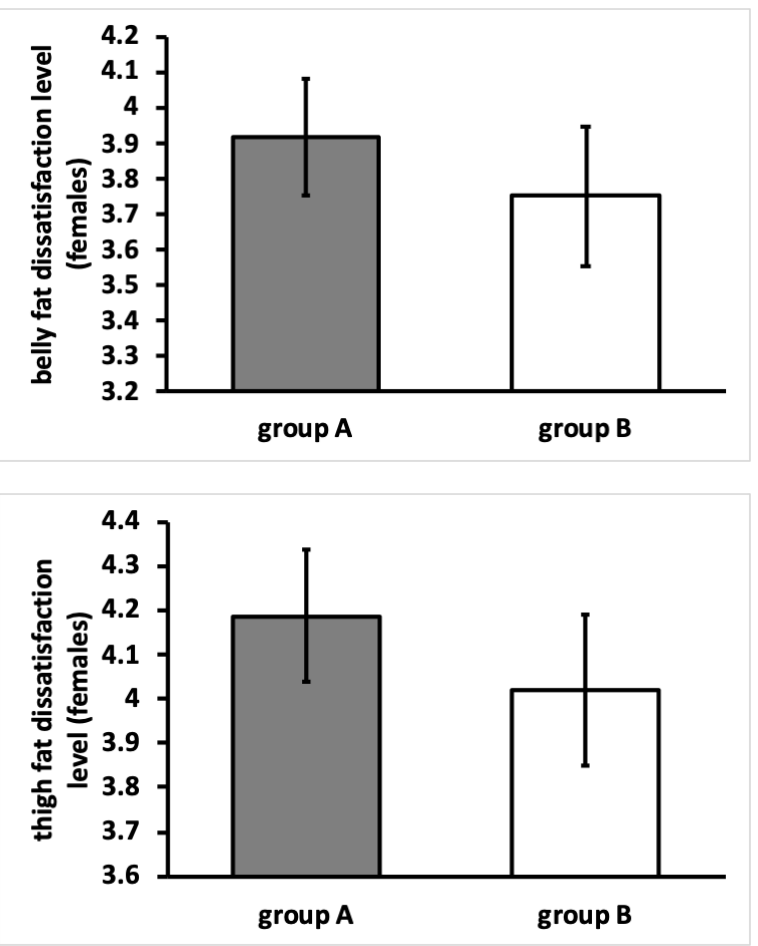

Figure 6 Specific Body Parts Dissatisfaction (Females)

H3a predicted that young females cared more about their thighs and stomachs in comparison to other body parts. And, H3b predicted that young males cared more about their chests and shoulders in comparison to other body parts.

According to Figure 6, the mean thin chest dissatisfaction level for young females increased from 3.042 to 3.375 , leading to a $10.947 \%$ increment rate. The p-value is $2.523 * 10^{\wedge}-16$, which is smaller than the significance level of 0.05 . Therefore, we have $95 \%$ confidence that the mean is significantly increased from group A to group B.

Furthermore, the mean narrow shoulder dissatisfaction level for young females increased from 2.458 to 2.771 , leading to a $12.734 \%$ increment rate. The p-value is $6.229 * 10^{\wedge}-19$, which is smaller than the significance level of 0.05 . Therefore, we have $95 \%$ confidence that the mean is significantly increased from group A to group B. 

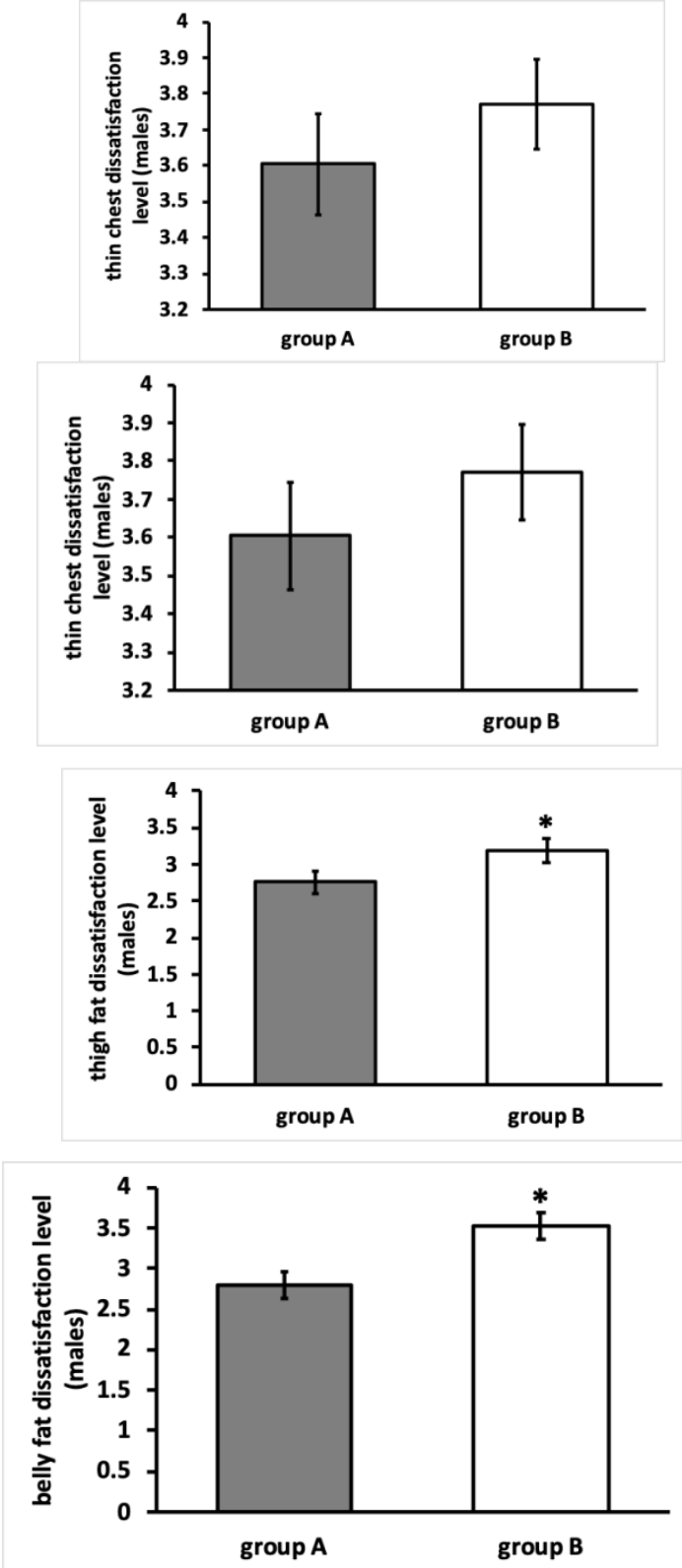

Figure 7 Specific Body Parts Dissatisfaction (Males)

On the other hand, as presented in Figure 7, the mean belly fat dissatisfaction level for young males increased from 2.792 to 3.519 , leading to a $26.039 \%$ increment rate. The $\mathrm{p}$-value is $1.202 * 10^{\wedge}-41$, which is smaller than the significance level of 0.05 . Therefore, we have $95 \%$ confidence that the mean is significantly increased from group A to group B. Moreover, the mean thigh fat dissatisfaction level for young males increased from 2.754 to 3.192 , leading to a $15.904 \%$ increment rate. The p-value is $2.583 * 10^{\wedge}-25$, which is smaller than the significance level of 0.05 . Therefore, we have $95 \%$ confidence that the mean is significantly increased from group A to group B.

We gained an unexpected but interesting result that females cared more about their chests and shoulders, while males cared more about their thighs and stomachs.
For other specific body parts, the variations were not significant enough to be studied.

Last but not least, H4a predicted that females kept diets in order to reach for pursuing body image and $\mathrm{H} 4 \mathrm{~b}$ predicted that males exercise in order to reach for pursuing body image. We partially confirmed hypothesis four. The research indicated males exercised for pursued body image, while females were neither affected nor altered to keep diets significantly.

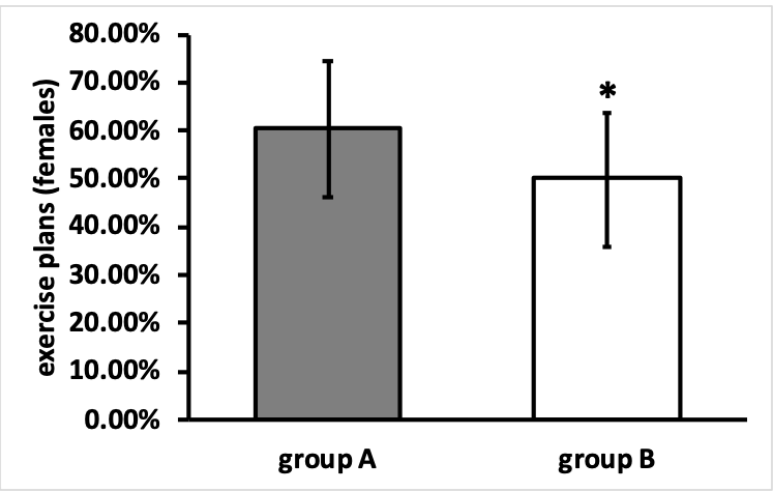

Figure 8 Exercise Plans (Females)

According to Figure 8, the percentage of young females who chose to exercise in group $\mathrm{A}$ is $60.42 \%$, while the percentage of young females who chose to exercise in group $\mathrm{B}$ is $50 \%$. The percentage was decreased by $10.42 \%$ from group A to group B. The $\mathrm{p}$ value is $1.318^{*} 10^{\wedge}-4$, which is smaller than the significance level of 0.05 . Therefore, we have $95 \%$ confidence that the mean is significantly decreased from group A to group B.

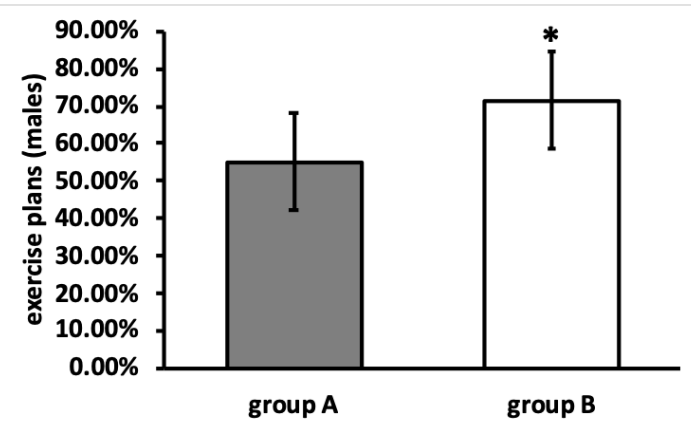

Figure 9 Exercise plans (Males)

Nonetheless, in Figure 9, the percentage of young males who chose to exercise in group A is $54.72 \%$, while the percentage of young males who chose to exercise in group B is $71.15 \%$. The percentage was increased by $16.43 \%$ from group A to group $\mathrm{B}$. The $\mathrm{p}$-value is $2.979 * 10^{\wedge}-11$, which is smaller than the significance level of 0.05 . Therefore, we have $95 \%$ confidence that the mean is significantly increased from group A to group B.

Thus, the results suggested that young females were unlikely to choose exercise plans to pursue ideal body 
images. On the other hand, young males are likely to choose exercise plans to pursue the ideal body image.

\section{CONCLUSION}

The relationship between social media and the young generation's body dissatisfaction has always been a crucial issue in an accelerating developed Internet era. This research was designed to examine the impact ideal bodies of celebrities on social media brought to young people with solid data rather than plain assumptions. In our study, differences were shown between the results and previous research. In the past, research demonstrated social media displayed a great role in influencing people's minds and actions. In other words, previous findings claimed social media caused people to develop severe anxiety and extreme diets. On the contrary, in our studies, neither females nor males revealed significant food anxiety after being exposed to the celebrity's ideal bodies. In addition, only males were perceived to exercise after the incentive, while females were not intended to either exercise or keep diets. Furthermore, in terms of the social stereotypes of ideal bodies for females and males, our results seemed to be ground-breaking. Apart from the stereotypes, the results stated that females perceived themselves more as the lack muscles and males perceived themselves as over-weighted. In addition, females cared more about their shoulders and chests, while males cared more about their thighs and stomachs, which were the exact opposite of the traditional stereotypes.

Nevertheless, we could reasonably refer to some implications from the results. Even though both females and males felt more anxious after being exposed to a celebrity's workout image, only a few practices were enacted. Thus, experiments should always take both mental states and behaviors into consideration before drawing any conclusions. Nonetheless, in the future, more rural areas and larger sample sizes should be included during the experiments. Besides, an experiment group that exposes a celebrity's ideal body without workouts can be included to control the variable. Furthermore, even though the young generation is the most active group on social media, researching other age groups facilitates building up the credibility of the results. Accordingly, a more valid and persuading inference can be made from the sample to the population.

Further studies are required to explore the possible reasons behind that might account for the unexpected results. For example, researching why females and males care more about some specific body parts over than others, which are opposite to the society expectations for females and males, by building various long-lasting tracked groups under different expectation sources from families, friends, and others.

All in all, contrary to the predictions, how females and males perceive their specific body parts and the evaluations they give seem to be deviated from the social norms. Therefore, decreased ideal body images exposure can barely alleviate mental anxiety or physical health issues.

\section{REFERENCES}

[1] Anderson, D. R., Huston, A. C., Schmitt, K. L., Linebarger, D. L., \& Wright, J. C. (2001). III. media use in adolescence. Monographs of the Society for Research in Child Development, 66(1), 25-35. doi:10.1111/1540-5834.00123

[2] Avalos, L., Tylka, T. L., \& Wood-Barcalow, N. (2005). The body appreciation scale: Development and psychometric evaluation. Body Image, 2(3), 285-297. doi:10.1016/j.bodyim.2005.06.002

[3] Blowers, L. C., Loxton, N. J., Grady-Flesser, M., Occhipinti, S., \& Dawe, S. (2003). The relationship between sociocultural pressure to be thin and body dissatisfaction in preadolescent girls. Eating Behaviors, 4(3), 229-244. doi:10.1016/s14710153(03)00018-7

[4] Brown, Z., \& Tiggemann, M. (2016). Attractive celebrity and PEER images on Instagram: Effect on WOMEN'S mood and body image. Body Image, 19, 37-43. doi:10.1016/j.bodyim.2016.08.007

[5] Bruner, J. S., \& Postman, L. (1949). Perception, cognition, and behavior. Journal of Personality, 18(1), 14-31. doi: $10.1111 /$ j.14676494.1949.tb01229.x

[6] Chung, S., \& Cho, H. (2017). Fostering parasocial relationships with celebrities on social media: Implications for celebrity endorsement. Psychology \& Marketing, 34(4), 481-495. doi:10.1002/mar.21001

[7] Eliasberg, W. G., \& Cooley, C. H. (1956). Social organization and human nature and the social order. The Journal of Criminal Law, Criminology, and Police Science, 47(4), 474. doi:10.2307/1140436

[8] Fardouly, J., Diedrichs, P. C., Vartanian, L. R., \& Halliwell, E. (2015). Social comparisons on social media: The impact of facebook on young women's body image concerns and mood. Body Image, 13, 38-45. doi:10.1016/j.bodyim.2014.12.002

[9] Garner, D. M., Olmstead, M. P., \& Polivy, J. (1983). Eating disorder inventory for anorexia nervosa and bulimia. PsycTESTS Dataset. doi:10.1037/t64315000

[10] Grabe, S., Ward, L. M., \& Hyde, J. S. (2008). The role of the media in body image concerns among women: A meta-analysis of experimental and 
correlational studies. Psychological Bulletin, 134(3), 460-476. doi:10.1037/0033-2909.134.3.460

[11] Groesz, L. M., Levine, M. P., \& Murnen, S. K. (2001). The effect of experimental presentation of thin media images on body satisfaction: A metaanalytic review. International Journal of Eating Disorders, 31(1), 1-16. doi:10.1002/eat.10005

[12] Hendrickse, J., Arpan, L. M., Clayton, R. B., \& Ridgway, J. L. (2017). Instagram and COLLEGE women's Body Image: Investigating the roles of appearance-related comparisons and intrasexual competition. Computers in Human Behavior, 74, 92-100. doi:10.1016/j.chb.2017.04.027

[13] Herman, C., \& Polivy, J. (2005). Normative influences on food intake. Physiology \& Behavior, 86(5), 762-772. doi:10.1016/j.physbeh.2005.08.064

[14] Ho, S. S., Lee, E. W., \& Liao, Y. (2016). Social network SITES, friends, and Celebrities: The roles of social comparison and celebrity involvement In ADOLESCENTS' body image dissatisfaction. Social Media + Society, 2(3), 205630511666421. doi:10.1177/2056305116664216

[15] Holland, G., \& Tiggemann, M. (2016). A systematic review of the impact of the use of social networking sites on body image and disordered eating outcomes. Body Image, 17, 100-110. doi:10.1016/j.bodyim.2016.02.008

[16] Jones, D. C., Vigfusdottir, T. H., \& Lee, Y. (2004). Body image and the appearance culture among adolescent girls and boys. Journal of Adolescent Research, 19(3), 323-339. doi:10.1177/0743558403258847

[17] Laken, A. (2009). Parasocial relationships with celebrities: An illusion of intimacy with mediated friends. Retrieved March 12, 2021, from https://digitalscholarship.unlv.edu/thesesdissertatio ns/962

[18] Madden, M., Lenhart, A., Cortesi, S., Gasser, U., Duggan, M., Smith, A., \& Beaton, M. (2020, August 17). Teens, social media, and privacy. Retrieved March 23, 2021, from https://www.pewresearch.org/internet/2013/05/21/t eens-social-media-and-privacy/

[19] Maltby, J., Giles, D. C., Barber, L., \& McCutcheon, L. E. (2005). Intense-personal celebrity worship and body image: Evidence of a link among female adolescents. British Journal of Health Psychology, 10(1), 17-32. doi:10.1348/135910704x15257

[20] McCabe, M., \& Ricciardelli, L. (2001). Parent, peer, and media influences on body image and strategies to both increase and decrease body size among adolescent boys and girls. Retrieved March 14, 2021, from https://pubmed.ncbi.nlm.nih.gov/11572302/

[21] Merton, R. K., \& Kitt, A. S. (1950). Contributions to the theory of reference group behavior. Continuities in Social Research: Studies in the Scope and Method of "The American Soldier", 40105.

[22] Mills, J. S., Polivy, J., Herman, C. P., \& Tiggemann, M. (2002). Effects of exposure to thin media images: Evidence of self-enhancement among restrained eaters. Personality and Social Psychology Bulletin, 28(12), 1687-1699. doi:10.1177/014616702237650

[23] Mintz, L. B., \& Betz, N. E. (1986). Sex differences in the nature, realism, and correlates of body image. Sex Roles, 15(3-4), 185-195. doi: $10.1007 / \mathrm{bf00287483}$

[24] Monteath, S. A., \& McCabe, M. P. (1997). The influence of societal factors on female body image. The Journal of Social Psychology, 137(6), 708-727. doi:10.1080/00224549709595493

[25] Raun, T. (2018). Capitalizing intimacy. Convergence: The International Journal of Research into New Media Technologies, 24(1), 99-113. doi:10.1177/1354856517736983

[26] Roberts, K. A. (n.d.). Relationship attachment and the behaviour of fans towards ce- lebrities [Electronic Version]. Applied Psychology in Criminal Justice, 3(1), 54-74.

[27] Singh, D., \& Young, R. K. (1995). Body weight, waist-to-hip ratio, breasts, and hips: Role in judgments of female attractiveness and desirability for relationships. Ethology and Sociobiology, 16(6), 483-507. doi:10.1016/0162-3095(95)00074-7

[28] Thompson, J. K., Heinberg, L. J., Altabe, M., \& Tantleff-Dunn, S. (1999). Exacting beauty: Theory, assessment, and treatment of body image disturbance. doi:10.1037/10312-000

[29] Tiggemann, M., \& Miller, J. (2010). The internet and adolescent girls' weight satisfaction and drive for thinness. Sex Roles, 63(1-2), 79-90. doi:10.1007/s11199-010-9789-Z

[30] Tiggemann, M., \& Slater, A. (2013). NetGirls: The Internet, Facebook, and body image concern in adolescent girls. International Journal of Eating Disorders, 46(6), 630-633. doi:10.1002/eat.22141

[31] Tiggemann, M., \& Slater, A. (2014). Dieting measure. PsycTESTS Dataset. doi:10.1037/t32235000

[32] Turner, R. H. (1955). Reference groups of futureoriented men. Social Forces, 34(2), 130-136. doi: $10.2307 / 2572827$ 